\title{
Long-term variations and trends in the polar E-region
}

Lindis Merete BJOLAND ${ }^{(1)}$, Yasunobu OGAWA ${ }^{(2)}$, Chris HALL ${ }^{(3)}$, Mike RIETVELD ${ }^{(4)}$, Unni Pia LøVHAUG $^{(1)}$, Cesar LA HOZ ${ }^{(1)}$, and Hiroshi MIYAOKA ${ }^{(2)}$

(1) Department of Physics and Technology, University of Troms $\varnothing-$ The Arctic University of Norway, Troms $\varnothing$, Norway

(2) National Institute of Polar Research, Tokyo, Japan

(3) Troms $\varnothing$ Geophysical Observatory, University of Troms $\varnothing$-The Arctic University of Norway, Troms $\varnothing$, Norway

(4) EISCAT Scientific Association, Ramfjordmoen, Norway

As the EISCAT UHF radar system in Northern Scandinavia started its operations in the early 1980s, the collected data cover about three solar cycles. These long time-series provide us the opportunity to study long-term variations and trends of ionospheric parameters in the high latitude region.

In the present study we have used the EISCAT Troms $\varnothing$ UHF data to investigate variations of the Hall conductivity and ion temperatures in the E-region around noon. Both the ion temperature and the peak altitude of the Hall conductivity are confirmed to depend strongly on solar zenith angle. However, the dependence on solar activity seems to be weak.

In order to search for trends in these parameters, the ion temperature and peak altitude of the Hall conductivity data were adjusted for their seasonal and solar cycle dependence. A very weak descent ( $\sim 0.2 \mathrm{~km} /$ decade) was seen in the peak altitude of the Hall conductivity. The ion temperature at $110 \mathrm{~km}$ shows a cooling trend ( $\sim 10 \mathrm{~K} /$ decade). However, other parameters than solar zenith angle and solar activity seem to affect the ion temperature at this altitude, and a better understanding of these parameters is necessary to derive a conclusive trend.

In this paper, we discuss what may cause the characteristics of the variations in the electric conductivities and ion temperatures in the high latitude region. 